\title{
COMPARAÇÃO ENTRE DADOS SELECIONADOS DE DOIS SISTEMAS DE COMUNICAÇÃO DE ACIDENTE DE TRABALHO NO MUNICÍPIO DE SÃO JOSÉ DOS CAMPOS
}

\author{
Carolina Tosetto Pimentel ${ }^{1}$ \\ Marielly Herreira González ${ }^{2}$
}

Valdir A. Alves ${ }^{3}$

Resumo: Neste texto, o objetivo é analisar dados da Rede Nacional de Atenção Integral à Saúde do Trabalhador (Renast) comparados com os dados de registro do Anuário Estatístico de Acidentes do Trabalho (AEAT) para o município de São José dos Campos nos anos de 2013 e 2014. Utilizando os dados do AEAT divulgada pela Previdência Social e o Ministério do Trabalho, pode-se verificar uma discrepância entre os dados relacionados a acidentes de trabalho desta pesquisa e aqueles registrados na base de dados da Renast, procedentes do Sistema Único de Saúde (SUS). A comparação mostrou que a AEAT aponta números de quase sete vezes os da Renast. Sugere-se que essa diferença se deva á subnotificação do registro de acidentes e a situação de desvalorização ao qual se encontra a Renast regional devido à falta de incentivos voltados para a área de saúde e segurança do trabalhador.

Palavras-chave: Acidentes de trabalho; Saúde e segurança do trabalhador; Agravos trabalho São José dos Campos.

\footnotetext{
${ }^{1}$ ETEP Faculdades - Pós-Graduação em Engenharia de Segurança do Trabalho, São José dos Campos/SP, Brasil. E-mail: carolinatosetto@hotmail.com.

2 ETEP Faculdades - Pós-Graduação em Engenharia de Segurança do Trabalho, São José dos Campos/SP, Brasil. E-mail: pandora_sjc@yahoo.com.br.

${ }^{3}$ ETEP Faculdades - Pós-Graduação em Engenharia de Segurança do Trabalho, São José dos Campos/SP, Brasil. E-mail: valdir.alves@etep.edu.br.
} 